\title{
Model Driven Analysis of the Biosynthesis of 1,4-butanediol from Renewable Feedstocks in Escherichia coli
}

\author{
ZSOLT BODOR ${ }^{1 *}$, SZABOLCS LANYI ${ }^{1,2}$, BEATA ALBERT ${ }^{1}$, KATALIN BODOR $^{2,3}$, AURELIA CRISTINA NECHIFOR $^{4 *}$, \\ ILDIKO MIKLOSSY ${ }^{1}$ \\ ${ }^{1}$ Sapientia Hungarian University of Transylvania, Faculty of Economics, Socio-Human Sciences and Engineering, Department of \\ Bioengineering, 1 Libertatii Sq., 530104, Miercurea Ciuc, Romania \\ 2University of Pecs, Faculty of Natural Sciences, Doctoral School of Chemistry, Ifjusag 6, 7624, Pecs, Hungary \\ ${ }^{3}$ Heineken Romania, 100 Harghita Str., 530154, Miercurea Ciuc, Romania \\ 4Politehnica University of Bucharest, Faculty of Applied Chemistry and Material Science, Analytical Chemistry and Environmental \\ Engineering Department, 1-7 Gheorghe Polizu Str., 011061, Bucharest, Romania
}

\begin{abstract}
Bio-based, environmentally benign production of commodity chemicals such as 1,4-butanediol (BDO) from renewable feedstocks is highly challenging due to the lack of natural synthesis pathways. Herein, we present a systematic model-driven evaluation of the production potential for Escherichia coli to produce BDO from renewable carbohydrates (glucose, glycerol). Computational analysis was carried out in order to decipher the metabolic characteristics under various genetic and environmental conditions. Optimal strain designs were achieved using only two (adhE2- alcohol dehydrogenase and cat/suCCD-4-hydroxybutyrate-CoA transferase/4-hydroxybutyryl-CoA ligase) heterologous reactions; highest yields were attained for: glucose $\sim 0.37 \mathrm{~g} \mathrm{~g}^{-1}$ (3 knockouts, anaerobically) and glycerol $\sim 0.43 \mathrm{~g} \mathrm{~g}^{-1}$ (4 knockouts, microaerobically). The maximum achievable production yield was over $95 \%$ of the theoretical maximum potential for glucose and over $75 \%$ for glycerol. In regards to the genome-scale metabolic model predictions, a metabolicallyengineered E. coli was created to analyze the new biosynthetic pathway stability and functionality. Considering the preliminary outcomes the strain and pathway is stable under fermentative conditions and a limited quantity of BDO 1 mg L-1 was obtained, therefore long-term adaptive evolution is mandatory. This study outlines a strain design and analysis pipeline -systems biology-based approach-for non-native compounds production strains.
\end{abstract}

Keywords: renewable feedstocks; bioconversion; 1,4-butanediol; COBRA, E. coli, strain design

There are limited resources of fossil deposits and the accelerated exploitation of these resources for fuel, energy and even as raw material for producing different chemicals raises serious environmental and sustainability concerns [1-3]. Supplementing petroleum consumption with renewable resources is, therefore, of critical importance in sustaining the growth of the chemical industry. On the other hand, the efficient use of valuable materials, byproducts generated during different processes [4], as well as the environmental pollutions (even at regional levels) [5-9] represent major challenges to be addressed.

The biosynthesis of value-added chemicals including biofuels, fine and commodity chemicals and pharmaceuticals from renewable feedstocks using microorganisms [10] could be a sustainable alternative to the current chemical synthesis. How ever, for industrial applications several key issues must be satisfied e.g. productions rate, yield and titer [11, 12]. One possible way to address these challenges is systems-based design of microorganisms, which aim is harnessing renewable sources and design new highly efficient mini cell factories that convert inexpensive feedstocks, by-products such as glucose, glycerol from different industries into important bio-based chemicals, like 1,4-butanediol (BDO) [13-16]. BDO production still relies primarily on chemical transformation of acetylene, propylene or butane (Reppe chemistry) $[1,13]$.

In this reaction one mole of acetylene reacts with two moles of formaldehyde to produce 1,4-butynediol (Eq. 1), after hydrogenation yielding 1,4-butanediol (BDO) (Eq.2).

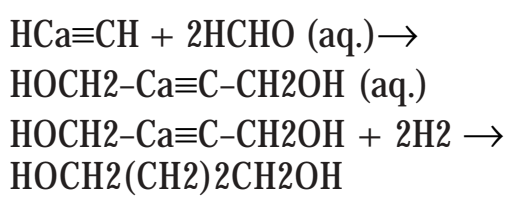

Reppe chemistry still accounts for about $40 \%$ of the global BDO capacity, key producers using this technology including BASF, Ashland (ISP) and DuPont.

BDO is an industrial solvent and important commodity chemical with a large range of applications including polyesters, plastics, fibers, $\gamma$-butyrolactone (GBL), lactones, tetrahydrofuran (THF) $[3,13,17]$. The bio-based BDO production achievements are excellently overviewed elsewhere [18]. Briefly, Genomatica Company uses an engineered microorganism for direct fermentation of carbohydrate feedstockes [1] to BDO, production over 18 $\mathrm{gL}^{-1}$ was achieved. On the other hand, BioAmber is focused on the production of bio-based succinate which then is converted to BDO [19] by catalytic hydrogenation technology.

The process developed by Genomatica demonstrates by far the power of biosynthesis but, unfortunately it is the only company which developed the process for commercial scale production $[1,18]$. Economically viable productions ( $>125 \mathrm{~g} \mathrm{~L}^{-1}$ for glucose, rate $>3.5 \mathrm{~g} \mathrm{~L}^{-1} \mathrm{~h}^{-1}$ and yield $0.4 \mathrm{~g}$ $\mathrm{g}^{-1}(80 \%$ of theoretical)) were achieved as reported by [3, 18], while less $1 \mathrm{~g} \mathrm{~L}^{-1}$ was obtained by [20] and a production rate of $2.12 \mathrm{mmol} \mathrm{gDW}^{-1} \mathrm{~h}^{-1}$ was reported by [11]. On the other hand, an alternate approach has recently been 
reported to produce $\mathrm{BDO}\left(12 \mathrm{gL}^{-1}\right)$ from xylose and glucose as co-substrates [15, 17, 21], arabinose, or galactoronate with titers up to $16.5 \mathrm{~g} \mathrm{~L}^{-1}$ [21]. The development of additional bio-based innovative and environmentally-friendly technologies for BDO synthesis is a stringent requirement.

A myriad of products were obtained using recombinant technology and different microbial host systems as E. coli, Saccharomyces cerevisiae [12], [22-28]: 1,4-butanediol $[1,15,21,29], 1,3-$ propanediol $[30,31]$, succinate [32, 33], 1,2-propanediol [34], isobutanol [35], etc. The bioconversion of renewable carbon sources such as glucose and glycerol for added-value chemical compounds brings many advantages: biomass valorification in case of glucose and use of glycerol resulted from biodiesel industry as side product during the transesterification process [ 3639].

Genome-scale metabolic models are widely used for rational designing strategies [40] and the outcomes (growth rate, metabolite flux, etc.) [41, 42] can be successfully predicted through constraint-based reconstruction and analysis (COBRA) approach [40, 4348].

The purpose of this study was to investigate how BDO production in $E$. coli using a simple heterologous biosynthetic pathway. To our knowledge, this study is the first attempt to characterize in detail this BDO pathway. A systematic in silico approach was used to metabolic engineering and for a detailed analysis of the BDO metabolism: an accurate genome-scale metabolic model of E. coli [49], implementation of the new pathway, optimization of the production potential (growth-coupled designs utilizing OptKnock [50] and GDLS [51] algorithms, identification of possible optimal environmental conditions using minimal medium that lead to optimal performance in BDO production. Using the modified metabolic model, we performed a large-scale computational study of growth-coupled production potential of BDO from renewable feedstocks. We have identified the best designs for glucose and glycerol considering the following criteria: production rate, yield, and engineering complexity. Diauxic growth was analyzed using dFBA [52, 53]. Preliminary laboratory experiments were carried out, the heterologous pathway for BDO production in E. coli was introduced and tested (ë-Red recombineering methods) [54, 55]. Considering the preliminary outcomes to achieve the in silico predictions further optimizations are required $[3,56$ 59].

\section{Experimental part}

Metabolic network reconstruction

The recently published and validated genome-scale metabolic reconstruction of $E$. coli ij 01366 [49] was utilized throughout the work. The impact of substrate uptake rate on cell metabolism and BDO production was studied by setting to 10 and $20 \mathrm{mmol}^{\mathrm{gDW}}{ }^{-1} \mathrm{~h}^{-1}$, respectively (these values are close to that observed experimentally) $[44,49,60,61]$.

Pathways were designed taking into consideration the previously published results and suggestions [ $1,29,62,63]$. Heterologous reactions were characterized using the available specific databases such as: Brenda, NCBI and EcoCyc. The new heterologous pathways were incorporated into the model following the established reconstruction protocol [64].

\section{Constraint-based modeling, flux balance analysis (FBA)}

BDO production was studied using constraint-based simulations which is commonly used in metabolic engineering for analyzing cellular metabolism under different circumstances [2], 42, 46, 65, 66]. Simulations were carried out by solving a linear optimization problem (LP) under steady-state (biologically-optimal flux distribution):

$$
\begin{aligned}
& \max Z=c^{T} v \\
& \text { subject to } S v=0 \\
& \left(\sum_{i} S_{i j} v_{i}=0\right) \\
& v_{l b}<v<v_{u b}
\end{aligned}
$$

where $Z$ is the objective function, $c$ is a vector of weights (the contribution of each reaction to the objective function), $S$ is the stoichiometric matrix with $m$ metabolites and $n$ reactions, $v$ flux vector with $n$ elements, $v_{b b}$ and $v_{u b}$ represent the lower and upper limits on the fluxes, respectively.

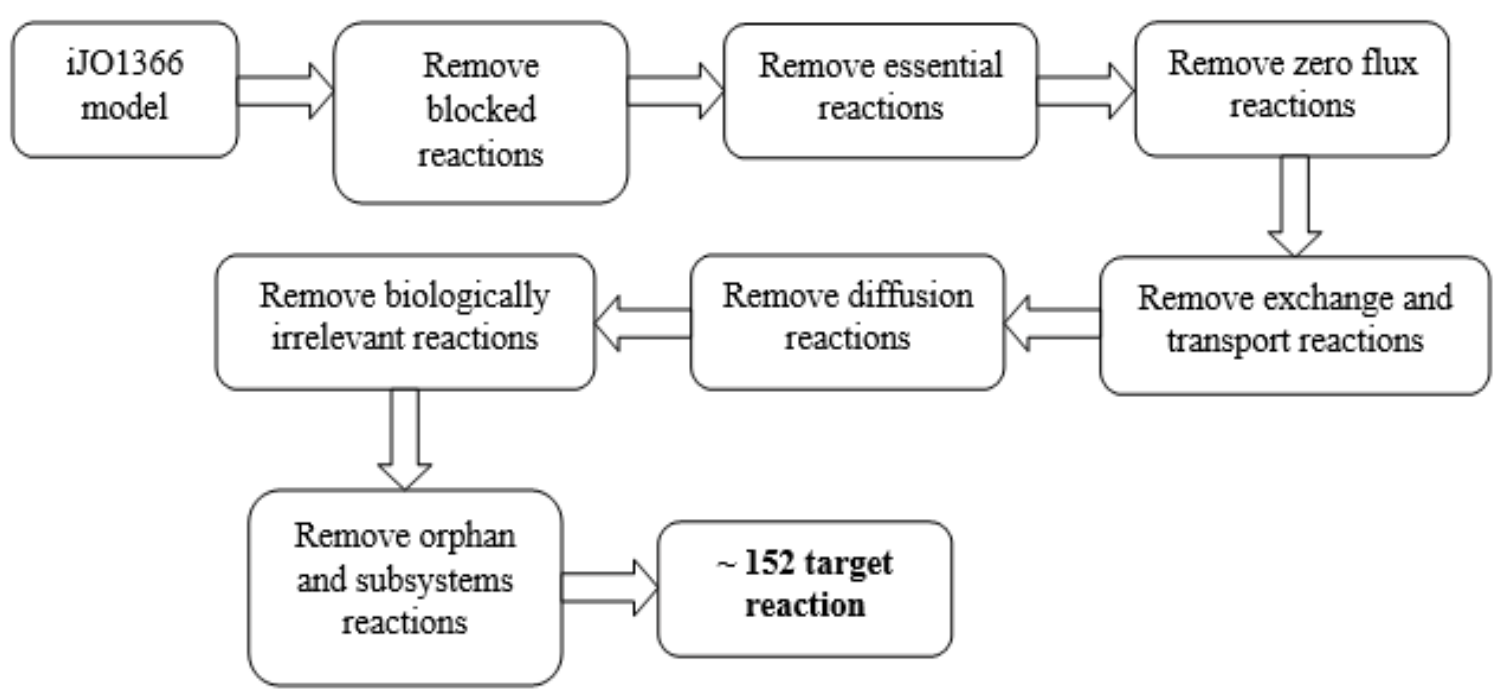

Fig. 1. Model pre-processing for strain design analysis and identification of target reactions for OptKnock and GDLS 
For all simulations two primary substrates were evaluated (glucose and glycerol), for each carbon source an uptake rate of 10 and $20 \mathrm{mmol}^{\mathrm{gDW}} \mathrm{DW}^{-1} \mathrm{~h}^{-1}$ was fixed $(60$

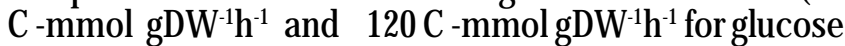
and $30 \mathrm{C}^{-}-\mathrm{mmol}^{-1} \mathrm{gDW}^{-1} \mathrm{~h}^{-1}$ and $60 \mathrm{C}^{-\mathrm{mmol}} \mathrm{gDW}^{-1} \mathrm{~h}^{-1}$ for glycerol), respectively. Both uptake rates were analyzed to decipher the importance of this constraint to the computations. The oxygen uptake rate was constrained to be $5 \mathrm{mmol} \mathrm{gDW}^{-1} \mathrm{~h}^{-1}$ to simulate microaerobic environmental conditions, otherwise it was set to 0 . All simulations were performed using MATLAB (The MathWorks Inc., Natick, MA, USA) and COBRA Toolbox $[53,67]$ software packages with TOMLAB CPLEX ((Tomlab Optimization Inc., San Diego, CA, USA) and GUROBI (Gurobi Optimizer version 6.0, Houston Texas) solvers.

The synthetic strain was optimized by bi-level optimization using OptKnock [50] and GDLS (search neighborhood size varied from 1 to 4) [51]. Simulations were run for two, three and four knockouts (for easy experimental implementation).

\section{Theoretical maximum production of BDO achievable in E. coli}

To determine the maximum production efficiency in $E$. coli the following modifications were made: a) constraining the substrate and environmental conditions (glucose, glycerol and microaerobic or anaerobic); b) absolute theoretical maximum was determined by setting the flux through biomass reaction (growth rate $(\mu)$ ) to $0 \mathrm{~h}^{-1}$ and to $0.1 \mathrm{~h}^{-1}$ a critical minimum growth rate (the flux which is necessary through the BOF core to obtain a functional strain); c) changing the objective function (maximization the flux through the target exchange reaction using FBA).

\section{Model preprocessing before strain optimization}

To reduce the computation time, reactions with no critical importance for gene knockouts were eliminated from the metabolic model, with the goal to reduce the computation time and to constrain the number of unrealistic designs [44, 68,69]. Pre-processing was condition specific and includes seven major steps Fig. 1.

After these modifications there still remained more than 200 reactions. To reduce the number near to 150 (a reasonable number for strain design) reactions were manually removed taking into account suggestions from the literature e.g. all reactions thathad been experimentally found to be essential for growth [44, [70-72].

\section{Optimization of BDO production}

The gene deletion strategies employed in this study consists of 3 basic sets of gene elimination: two, three and four reaction knock-outs while the growth rate was set to $0.1 \mathrm{~h}^{-1}$. Using the optimization algorithms presented, the production of the desired product becomes an obligatory by-product to sustain the specific growth rate. Strain designs can be examined using different production phenotypes: production rate, product yield and substratespecific productivity (SSP).

$$
S S P=Y_{p / s} * \text { growth rate }\left(\frac{\mathrm{mol}}{\mathrm{mol}} * h^{-1}\right)
$$

\section{dFBA (dynamic FBA)}

dFBA is widely used in metabolic engineering for analysis, control and optimization of biochemical processes $[52,73]$. Is an extension of FBA and it is modified in such a way that the external compounds concentrations are allowed to change over time according to the welldefined dynamic balance equations [73]. In order to study the effect of substrate uptake on cellular metabolism, including BDO production too, simulations were carried out with 10 and $20 \mathrm{mmol}$ substrate uptake and the target metabolite production and diauxic shift was analyzed to identify which compounds are secreted and subsequently metabolized- considerable attention accorded to BDO production.

\section{Experimental procedure}

The Escherichia coli K12 MG1655 bacterial strain used in this study was purchased from Deutsche Sammlung von Mikroorganismen und Zellkulturen GmbH (DSMZ 18039). Cultivation conditions, chromosomal gene deletions and analytical procedures were conducted following the procedures described elsewhere [33, 54], 55]. Briefly, replicate fermentations were performed with $1 \mathrm{~L}$ M9 minimal medium in a 2-L Sartorius Biostat ${ }^{\circ} A$ Plus Bioreactor, using a BioPAT ${ }^{\circledR}$ MFCS/DA data acquisition and control system, supplemented with $5 \mathrm{~g} \mathrm{~L}^{-1}$ glucose or glycerol. The temperature was held at $37^{\circ} \mathrm{C}, \mathrm{pH} 7$ and $\mathrm{CO}_{2}$ was purged through the medium to create anaerobic phase and for microaerobic phase the dissolved oxygen was set to $5 \%$ of saturation and maintained by sparging the reactor headspace with air.

Genes coding for enzymes of the new BDO biosynthetic (adhE2 (aldehyde/alcohol dehydrogenase from Clostridium acetobutylicum) and suCCD (succinyl-CoA synthetasefrom $E$. coli) were transformed into production strains by petDuet-1-adhE2-sucCD plasmid vector. In the first phase at the proof of concept level mutant $E$. coli strains have been created by deletion, using genetic engineering methods of coding sequences for: pyruvate-formate lyase (pfl), lactate dehydrogenase (Idh) and alcohol dehydrogenase (adhE). Inactivation of named genes has been carried out by the homologous recombination-based ë-Red method [54]. Plasmids (5 Strain Wanner Lambda Red Gene Disruption Kit) were purchased from the $E$. coli Genetic Stock Center (Yale University).

Protein expressions were induced with $1 \mathrm{mmol}$ IPTG in the mid-log phase. Metabolites were analyzed by an Agilent Infinity 1260 chromatography system, equipped with UVVis and RID detectors. Glucose, BDO, succinate and acetate determination was carried out using a Coregel $87 \mathrm{H} 3$ column. More details regarding the construction of strain, plasmids, fermentation conditions and analytical tools can be found in [55].

\section{Results and discussions}

Metabolic engineering of microorganisms is a powerful tool, continuously growing and widely used to create new high-performance cellular systems that convert abundant and inexpensive carbohydrates into bio-based fuels, chemicals and polymers [12]. As stated above, different renewable feedstocks such as glucose, sucrose, biomass hydrolysate, D-xylose, L-arabinose, and D-galacturonate were used for bio-based BDO production using metabolically engineered host chassis such as $E$. coli. On the other hand, glycerol is becoming more prevalently available from biodiesel production [36, 74]. To obtain BDO from glycerol brings many advantages: glycerol is produced as a by-product of biodiesel fuel production, its low price make glycerol an attractive carbon source, fuels and chemicals can be produced from glycerol at higher rates than from common sugars because the degree of reduction per carbon of glycerol is significantly higher than that of glucose for example [75, 76]. There are predictions that glycerol produced annually will increase in the future $[14,36]$ and the development of different bio-based 
processes being able to convert low-priced glycerol into higher value products is considered as a big challenge and excellent opportunity.

In order to address these issues, to compare the effect of different carbon sources, uptake rates a systematic workflow was developed as follows: I. heterologous pathway analysis and implementation on model; II. testing the production capabilities of the pathway (maximal theoretical yield) using various production environments e.g. substrate, oxygenation; III. strain design computations utilizing the OptKnock and GDLS algorithms; IV. identification and rank order the reactions that primarily control the flux toward BDO; $V$. analysis of diauxic growth and BDO production dynamics and finally, laboratory experiments were carried outto introduce the heterologous pathway, to knockout and test the mutant strains stability.

\section{Biosynthetic metabolic pathway reconstruction}

Since there is no natural pathw ay for BDO production in any known organism the biosynthesis can be realized only with heterologous pathways. One of the key issues during pathway design are cofactor regeneration and reduction of by-products.

The heterologous pathway consists of three basic reactions (Fig. 2). Starts from Krebs cycle intermediate succinyl-COA and then it is transformed to 4hydroxybutyrate by the COA and NADH dependent double specificity enzyme alcohol dehydrogenase (adhE2) from Clostridium acetobutylicum (first reduction). 4-HB is a key intermediate and it is possible to be secreted by the cell, however if there is sufficient pool the reaction will take place (forward) and the 4-hydroxybutyrate-CoA transferase converts 4-HB to 4-hydroxybutyryl-CoA resulting acetic acid from acetyl-CoA $[1,63]$. This enzyme is not found in $E$. coli and should be expressed from Clostridium kluyveri [1].
Alternatively, 4-HB can be converted to 4-HB-CoA by codonoptimized suCCD -4-hydroxybutyryl-CoA ligase (4hydroxybutyryl-CoA synthetase) from $E$. coli. The last transformation is the second reduction step catalyzed by CoA and NADH dependent alcohol dehydrogenase similar to first reduction. NADH regeneration is critical to the cell to maintain the redox potential and here four NAD will be produced during oxidation.

In figure 2 is presented one of the biosynthetic pathways giving the highest production rate, however different alternative combinations were also tested (not presented here).

In silico analysis of BDO production potential in E. coli

The new biosynthetic pathway is inactive and alternative native pathways are activated (acetate, formate or ethanol). One reason could be that these pathways are more energetically favorable. To overcome this, bi-level optimization should be carried outwith internal and external optimization [50]. First, the pathway efficiency was evaluated by performing an initial theoretical analysis (production potential landscape) to define the maximum production potential for BDO and if homofermentation is possible under previously defined conditions (Fig. 3). This was necessary to evaluate the strain designs efficiency based on substrate availability and oxygenation rate. As we expected the maximum theoretical yield was found under microaerobic conditions for both substrates. By eliminating the oxygen from the environment akin tendency was achieved; higher yield for glucose. The maximum weight yield $\left(\mathrm{g} \mathrm{g}^{-1}\right)$ is higher for glycerol under microaerobic conditions thanks to its reduced state, hence the highest theoretical maximum yield was achieved with $20 \mathrm{mmol}$ substrate uptake rate. On the other hand, homofermentation was possible only for microaerobic

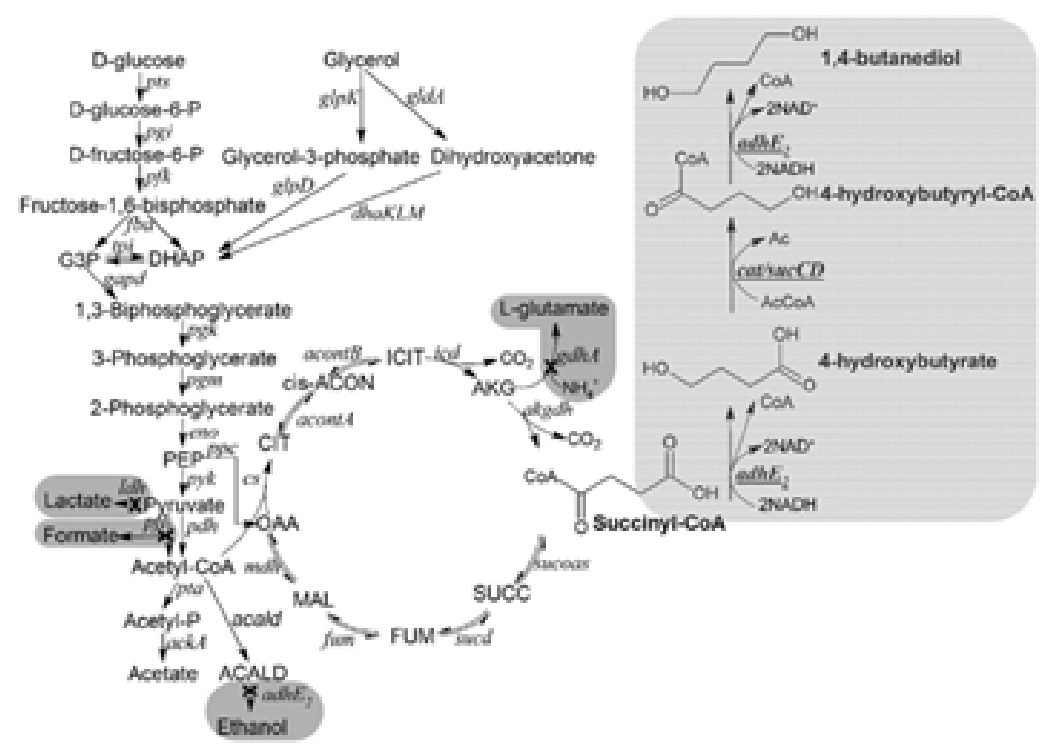

Fig.2. Most important metabolic pathways involved in glucose and glycerol metabolism, the new proposed biosynthetic pathway of BDO (in dotted background) and metabolic engineering strategies for the production of BDO.

Relevant heterologous reactions involved in BDO synthesis are represented in italics and underlined. Reactions to be eliminated are represented by a black $X$ and dark background (fig. 2).

Abbreviations: pts-D-glucose transport via PEP:Pyr PTS (periplasm); pgi -glucose-6-phosphate isomerase; pfk-phosphofructokinase; fba fructose-bisphosphate aldolase; tpi -triose-phosphate isomerase; gapd glyceraldehyde-3-phosphate dehydrogenase; glpK -glycerol kinase; gldA -glycerol dehydrogenase; glpD -Sn-glycerol-3-phosphate dehydrogenase; dhaKLM -dihydroxyacetone kinase; pgk -phosphoglycerate

kinase; pgm -phosphoglycerate mutase; eno -enolase; ppc -phosphoenolpyruvate carboxylase; pyk -pyruvate kinase; Idh-lactate

dehydrogenase; pfl -pyruvate formate lyase; pdh -pyruvate dehydrogenase; pta -phosphotransacetylase; ackA - acetate kinase; acald acetaldehyde dehydrogenase (acetylating); adhE2 -alcohol dehydrogenase (ethanol); cs -citrate synthase; acontA -aconitase (half-reaction A, Citrate hydro-lyase); acontB -aconitase (half-reaction B, Isocitrate hydro-lyase); icd -isocitrate dehydrogenase (NADP); akgdh -2-0xogluterate dehydrogenase; sucoas -succinyl-CoA synthetase (ADP-forming); sucd -succinate dehydrogenase (irreversible); fum -fumarase; mdh -malate dehydrogenase; cat -catalase; sucCD -succinyl-CoA synthetase. From [55] with permission 
conditions using substrate consumption of $10 \mathrm{mmol}$ (Fig.3). The advantage of homofermentation is that requires less effort to separate the target compound (the major byproduct resulted was acetate).It was pointed out that acetate needs to be recycled in form of Ac-CoA [3] by $E$. coli using the well-known acetate recycling pathways [77].

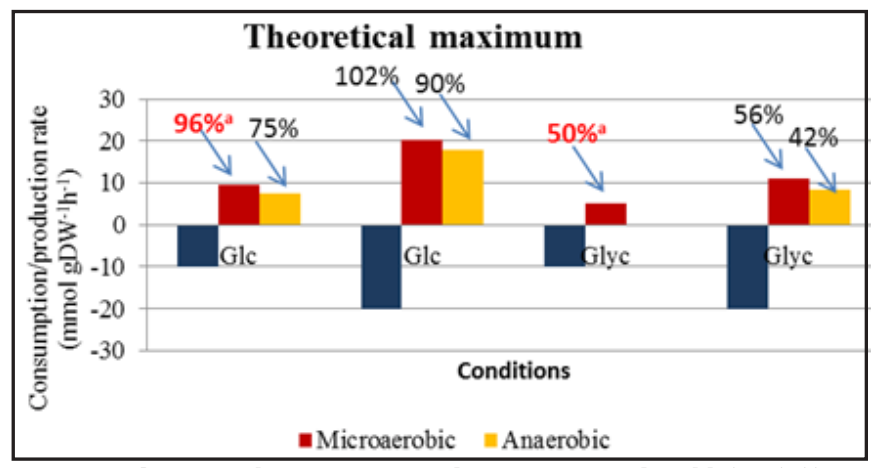

Fig.3. Theoretical maximum production rate and yield $\left(\mathrm{Y}_{\mathrm{p} / \mathrm{s}}(\%)\right)$ under various environmental conditions, Glc and Glyc represents glucose and glycerol, alndicates conditions where homofermentation is possible

Further analyses are necessary to elucidate the acetate effect on fermentation during laboratory experiments. Yields $\left(\mathrm{g} \mathrm{g}^{-1}\right)$ for each substrate and oxygenation condition were as follows: glucose $10 \mathrm{mmol} \# 20 \mathrm{mmol}$ microaerobic $0.49 \# 0.52$, anaerobic $0.39 \# 0.46$; glycerol $10 \mathrm{mmol} \# 20$ $\mathrm{mmol}$ microaerobic $0.50 \# 0.56$, anaerobic N/A\#0.42. As disclosed herein, under anaerobic conditions and $10 \mathrm{mmol}$ glycerol uptake rate we were unable to predict a stable theoretical maximum. Higher yields were predicted on both substrates during microaerobic simulations in agreement with previous studies [68].

\section{Strain design, metabolic engineering of the host strain}

The consequence of the new biosynthetic pathway on host organism metabolism was explored, followed by the design of mutantstrains being capable for $\mathrm{BDO}$ production. The recent metabolic model of E. coli K12 MG1655 [49] incorporates 2250 reactions and 1366 genes.

To identify the metabolic engineering targets for improved production of BDO a combination of two different optimization algorithms was used namely OptKnock and GDLS, with the conditioned model of ij 01366. Several optimization strategies were suggested by which increased BDO production could be achieved.

Both algorithms -limited to a maximum number knockout of four- identified strain designs with maximum of two, three and four knockouts that could couple BDO production to growth while a maximum growth, energy generation and BDO production is maintained. With reduced target reaction number each simulation was allowed to run to completion, so all combinations were analyzed. The selected strain designs -including the maximum growth-coupled yield results- from OptKnock and GDLS are summarized in Figure 4 and Figure 5.

OptKnock and GDLS al gorithms identified strain designs with coupled BDO production to growth, for microaerobic and for anaerobic conditions with two, three and four knockouts, respectively. In total 99 different reaction knockouts were identified for glucose across all defined environmental conditions. Growth-coupled designs selected for further analyses have been modified in order to block the synthesis of competing metabolites (formate, ethanol, lactate).
The major ubiquitous by-product almost in each case was acetate. What is more important is that the growth was tended to remain high which could be a key factor in biotechnologically and industrially important strain designs. One of the most frequently participating enzymes in strain designs is the pfl, adhE2, acald, tkt2, ldh and pgi. These reactions are critical to divert carbon flux toward BDO and they are connected to the central carbon metabolism [44, 68]. The highest yield was estimated for anaerobic conditions $\sim 0.37 \mathrm{~g} \mathrm{~g}^{-1}$ (C-mol yield 0.48 ); for microaerobic conditions the yield was approximately $0.19 \mathrm{~g} \mathrm{~g}^{-1}$ (C-mol yield 0.26 ) (10 mmol uptake) and $0.28 \mathrm{~g} \mathrm{~g}^{-1}$ (C-mol yield $0.37)$ (20 mmol uptake), respectively.

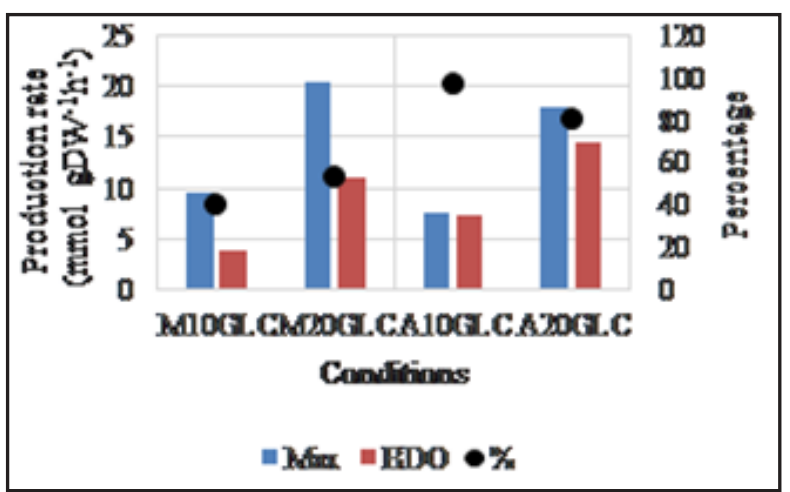

Fig. 4. Relationship between theoretical maximum and newly designed strains using OptKnock/GDLS under different environmental conditions on glucose. Abbreviations: M10GLC and A10GLC-microaerobic and anaerobic 10 and $20 \mathrm{mmol}^{\mathrm{gDW}} \mathrm{h}^{-1} \mathrm{~h}^{-1}$ glucose uptake rate, respectively

Similar results were reported in literature which has already been experimentally implemented [1], but with four knockouts. Substrate uptake rate is an important issue and should be carefully considered during experiments as suggested by [78, 79].

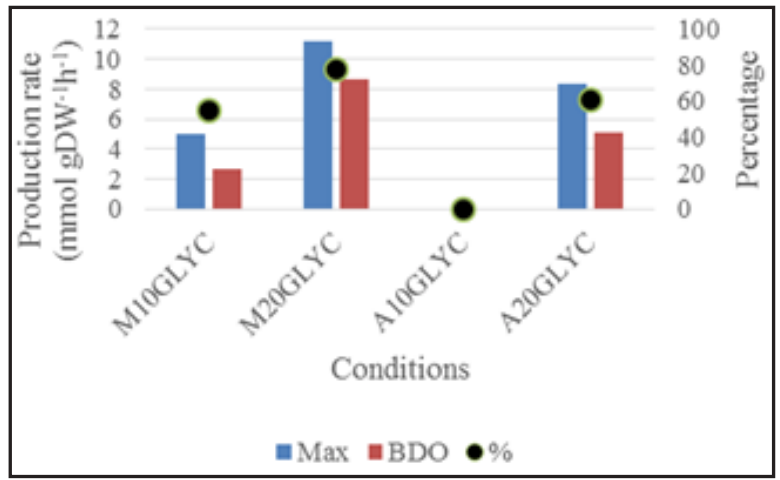

Fig.5. Relationship between theoretical maximum and newly designed strains using OptKnock/GDLS under different environmental conditions on glycerol. Abbreviations: M10GLYC and A10GLYC-microaerobic and anaerobic 10 and $20 \mathrm{mmol} \mathrm{gDW}^{-1} \mathrm{~h}^{-1}$ glycerol uptake rate, respectively

When comparing these two different oxygenation conditions the average yield for anaerobic environment was approximately $30 \%$ higher than the yield for microaerobic, respectively. In contrast to previous studies $[44,68]$ we found that in our case the maximum achievable yield was not significantly higher for designs with four knockouts compared to three knockouts strains. This pathway has more than $21 \%$ higher growth-coupled production potential than pathways presented earlier by [68] for the designs with equal knockouts (3 KO-anaerobic conditions). However, under microaerobic conditions a 16\% higher growth coupled yield was observed for ECOM strain [68]. A strong correlation was identified between the number of 
deletions and growth rate, namely that even if growthcoupled production is possible there is still a considerable growth cost (e.g. NADPH depletion) [80], the productivity depends on oxygenation as stated out earlier [11]. However, under strict anaerobic conditions further optimizations are needed because the designed BDO production strains growth rate could be blocked by simultaneous deletion of adhE2, Idh, and pfl [1, 11].

Next, simulations were carried out to design strains for glycerol, to identify the substrate/targets pairs. The combination ( $a d h E 2$, pfl, Idh) was not found as an optimal one by OptKnock and GDLS evaluations. BDO production from glycerol using the aforementioned reactions ( pfl, $a d h E 2,(d h)$ is impassable, especially under anaerobic conditions where growth rate is diminished $\left(<0.1 \mathrm{~h}^{-1}\right)$. With these modifications the carbon and energy flux cannot be connected to the new biosynthetic pathway efficiently, as long as large amount of carbon is lost in form of L-valine (amino acid secreted into the medium). One reason could be that the flux through $p p c$ (phosphoenolpyruvate carboxylase) and even pdh (pyruvate dehydrogenase) is not high enough to consume all the pyruvate generated ( $p f l$, Idh were eliminated- e.g. the lactate pathway allosteric activation is blocked), resulting in L-valine overflow [81]. To decipher the optimal knockouts, simulations were carried out in a manner similar to that used for glucose, using two, three and four knockout designs. Growthcoupled designs were identified for microaerobic conditions with four knockouts ( $p f l$, adhE2, Idh, gdhA). The main by-product was acetate which is a challenging byproduct since it is connected to BDO production (reaction catalyzed by cat/sucCD-4-hydroxybutyrate is converted to 4-hydroxybutyril $\mathrm{CoA}$ ), on the other hand the elimination (acetate pathway) drastically reduced the biomass formation. As presented by [3] to minimize acetate production and simultaneously optimize BDO production the expression level of ackA-pta should be optimized, in total 62 knockouts were identified. The most frequently enzyme was pfl followed by adhE2, glyk, acald and tkt2 (Fig.6). Yields were calculated for conditions with highest production rate (microaerobic) taking into consideration the substrate consumption ( 10 and $20 \mathrm{mmol}$ uptake rate): $0.26 \mathrm{~g} \mathrm{~g}^{-1}$ (C-mol yield 0.36 ) and $0.43 \mathrm{~g} \mathrm{~g}^{-1}$ (C-mol yield $0.58)$, respectively. As expected, no optimal strain design was found under anaerobic conditions. Higher substrate uptake rate significantly increased the growth-coupled yield, a difference of approximately $61 \%$ was identified. In order to figure outthe growth-coupled production potential of the new biosynthetic pathway our results were compared to the already reported yields. With this simple pathway the yield ( $\mathrm{C}-\mathrm{mol}$ 0.58) was close to the yield values obtained by [68] (0.598 C-mol with $4 \mathrm{KO}$ ).

When using glycerol as sole carbon source under microaerobic conditions the production yield was higher compared to glucose approximately $39 \%(10 \mathrm{mmol}$ ) and $57 \%$ ( $20 \mathrm{mmol}$ ), respectively. One reason could be that during glycerol uptake NADH and NADHPH is generated [68].

Looking at the flux distributions considerable differences were also observed in the values of $p p c$ fluxes, in mutant strains the flux was nearly 6,10 and 7 fold higher compared to wild-type under microaerobic, anaerobic (glucose) and microaerobic conditions (glycerol), respectively.

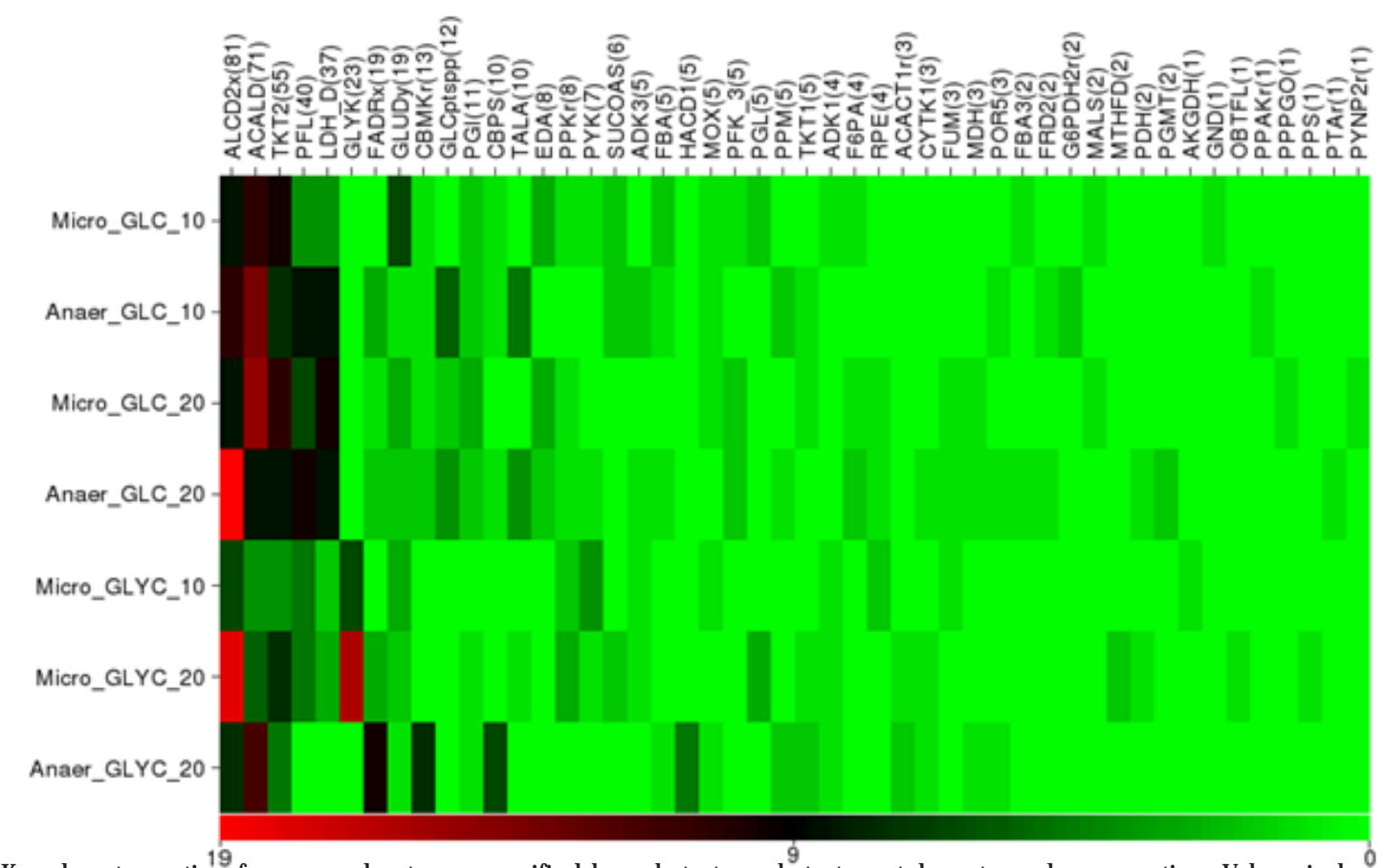

Fig.6. Knock out reaction frequency heatmap specified by substrate, substrate uptake rate and oxygenation. Values in brăckets represent the global number of designs where the specific reaction was knocked out

Abbreviations: GLCptspp- D-glucose transport via PEP:Pyr PTS (periplasm), PGI- glucose-6-phosphate isomerase, TALA- transaldolase, EDA2-dehydro-3-deoxy-phosphogluconate aldolase, PPKr- polyphosphate kinase, PYK- pyruvate kinase, SUCOAS- succinyl-CoA synthetase (ADPforming), ADK3- adentylate kinase (GTP), HACD1- 3-hydroxyacyl-CoA dehydrogenase (acetoacetyl-CoA), MOX- malate oxidase, PFK_3phosphofructokinase (s7p), PGL- 6-phosphogluconolactonase, PPM- phospho-pentomutase, TKT1- transketolase, ADK1- adenylate kinase, F6PA- fructose 6-phosphate aldolase, RPE- ribulose 5-phosphate 3-epimerase, ACACT1r- acetyl-CoA C-acetyltransferase, CYTK1- cytidylate

kinase (CMP), FUM- fumarase, MDH- malate dehydrogenase, POR5- pyruvate synthase, FBA3- Sedoheptulose 1,7-bisphosphate D-

glyceraldehyde-3-phosphate-lyase, FRD2- fumarate reductase, G6PDH2r- glucose 6-phosphate dehydrogenase, MALS-malate synthase, MTHFD- methylene-tetra-hydrofolate dehydrogenase (NADP), GND- phospho-gluconate dehydrogenase, OBTFL- 2-0xo-butanoate formate lyase, PPAKr- propionate kinase, PPPGO- protoporphyrinogen oxidase (aerobic), PPS- phospho-enolpyruvate synthase, PTAr- phosphotransacetylase, PYNP2r- pyrimidine-nucleoside phos-phorylase (uracil) 
As expected, the production potentials (designed strains) were under the maximum achievable theoretical yield, one reason could be that more regulations are needed at different levels e.g. fine tuning regulation of gene expression, optimizing the relative expression levels, etc. [11].

Substrate-specific productivity for a given condition

As suggested by [11] when engineering E. coli for BDO production many factors have to be considered, such as enzyme activity, substrate uptake, by-products, etc. SSP was examined to better understand the interactions between yield, production rate and growth rate. Using this method growth rate is implemented into the calculations and optimal design can be identified. Analyzing the results it is clear that the best SSP design was obtained for microaerobic conditions with glucose uptake rate of 20 $\mathrm{mmol}$. Glycerol seems to be a good candidate for microaerobic conditions where the resulted SSP was 0.1.
The highest SPP was obtained for glucose under microaerobic conditions 0.32 , however the anaerobic results are also important, 0.22 SPP. Another essential parameter or factor that should be taken into account is that, how appropriate are the theoretical maximum production results with our newly designed strains performance.

The difference between microaerobic and anaerobic conditions is significant, the percentage without oxygen is 2.65 fold higher. Changing the uptake rate there is a 1.57 fold difference. What is more important is that the percentage of the theoretical maximum was only higher for $20 \mathrm{mmol}$ uptake under microaerobic conditions (47.10 against 33.63).

On the other hand, the BDO production from glycerol ( 10 and $20 \mathrm{mmol}$ uptake rate) could be coupled to growth microaerobically with $\sim 46 \%$ and $\sim 68 \%$ of the theoretical maximum potential achievable, respectively. The allowance of more glycerol enter into the cell resulted a
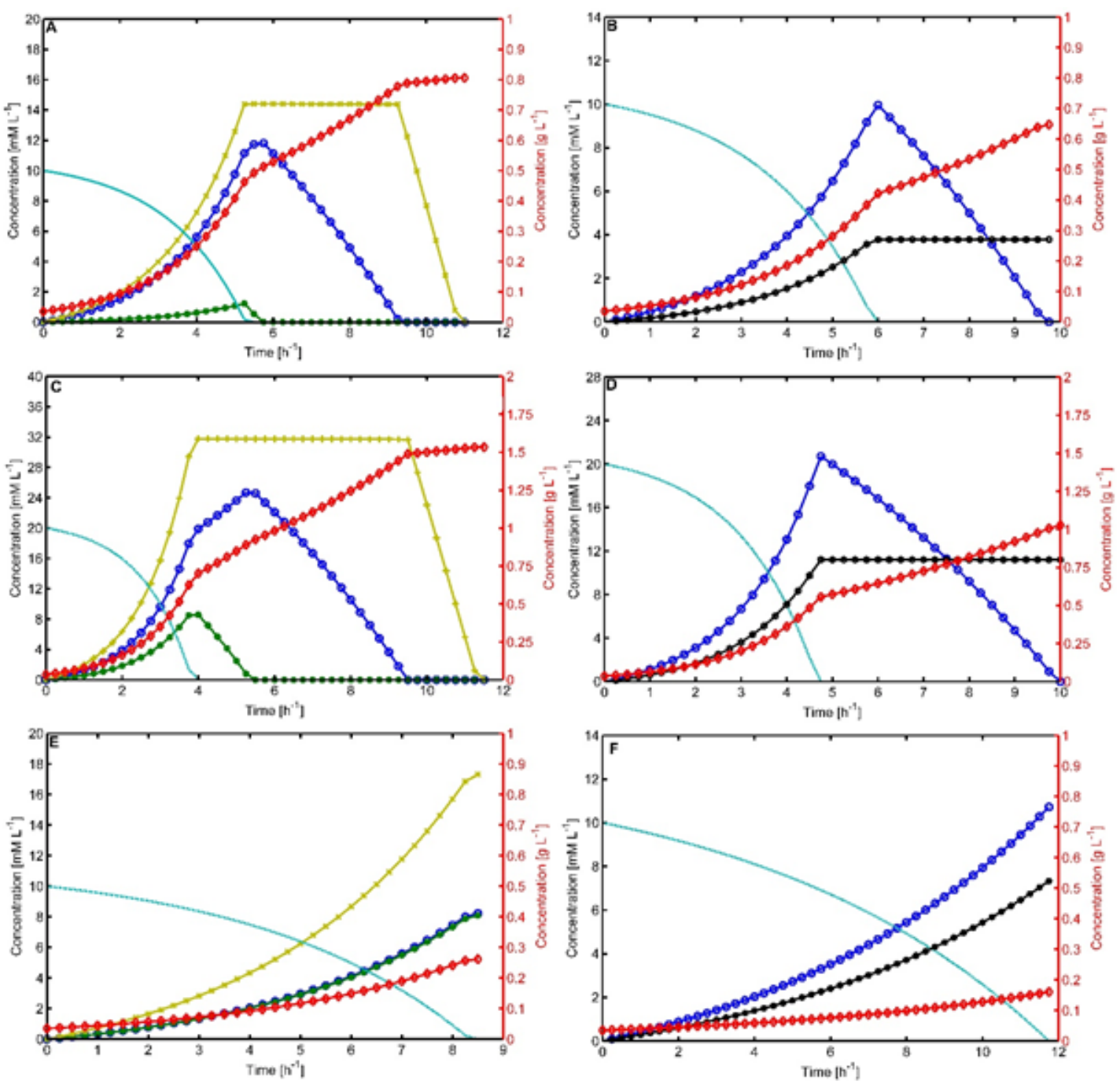

Fig. 7. Model predictions using dFBA for microaerobic and anaerobic conditions (glucose)

Microaerobic: WT- A, C, mutant- B, D; Anaerobic: WT- E, G, mutant- F,H
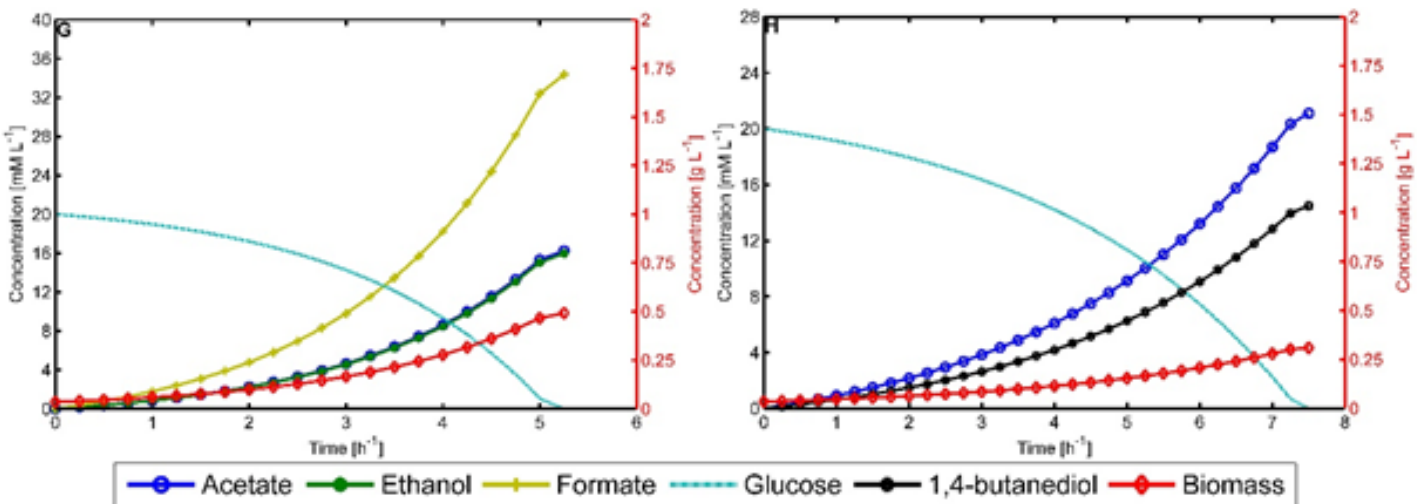

http://www.revistadechimie.ro 
significant increase, more than $47 \%$. During anaerobic conditions growth coupling is only achievable with more complex metabolic interventions e.g. over and under expression, regulation, etc. Surprisingly additional biologically relevant knockouts are no longer beneficial to increase yield, the increase in BDO production will decrease grow th rate below the critical point $\left(0.1 \mathrm{~h}^{-1}\right)$. One reason could be that biomass precursors and energy cannot be anymore generated in sufficient quantities.

\section{Dynamic FBA for wild-type and mutant strains}

dFBA was used to simulate batch growth in minimal media conditions with a sole carbon source (glucose or glycerol) for wild-type and mutant strains. Fig. 7 shows in silico predictions for 3 and 4 gene deletions. Diauxic growth (shift) was predicted only for microaerobic conditions on both substrates, where the secreted metabolites were subsequently metabolized. Varying the substrate concentration changes were observed in batch time as expected. Exponentially growing BDO production was predicted when glucose or glycerol was available.

BDO production in wild-type (with heterologous pathway) is impossible even if the oxygen is eliminated from the system (Fig. 7). Therefore, the 50\% reduced growth is attributed to the lack of oxygen. Under microaerobic conditions the system was limited by glucose and oxygen, when glucose was nearly completely consumed (at $5.3 \mathrm{~h}$ and $4 \mathrm{~h}$ respectively) the switch to ethanol and acetate utilization began following by formate consumption and the growth rate was linear not exponential as in case of glucose [52]. What is important is that under anaerobic conditions the batch was longer for glucose, however by increasing the substrate initial concentration the batch time was reduced from $8.5 \mathrm{~h}$ to $5.3 \mathrm{~h}$. It can be concluded that enhanced production is predicted for all the manipulations, higher without oxygen and with increased substrate uptake, however the biomass yield will be reduced in each scenario (the optimal conditions should be selected during experiments taking into account the case by case purposes). After the elimination of competing metabolites the batch time was shorter ( $10 \mathrm{~h}$ ) compared to wild-type (12 h), but a longer glucose depletion time was observed ( $6 h$ and $4.8 h$ ) compared to wild-type ( $5.3 \mathrm{~h}$ and $4 \mathrm{~h}$ ) under microaerobic conditions. Similar to previous results longer batch-time was predicted for anaerobic conditions. Large differences were observed in the BDO yields between environmental conditions. Consequently, optimal performance is dependent both on metabolic engineering strategies and environmental conditions.

Figure 8 presents the effect of glycerol uptake rate and the lack of oxygen on BDO production. It may be seen that genetic engineering did not influence the batch time and similar to glucose the glycerol consumption was longer than in wild-type ( $8.3 \mathrm{~h}$ and $7 \mathrm{~h}$ ). The glycerol batch time was longer compared to glucose due to slower growth on this substrate.

All manipulations produced enhanced BDO production under microaerobic and anaerobic conditions, however at the expense of reduced cellular growth.

\section{Production of BDO from glucose and glycerol}

The main objective, at the proof-of concept level, was to achieve a functional BDO pathway and eliminate the competing by-products to divert the carbon flux toward BDO. As stated earlier [55] the biosynthetic pathway of BDO was stable under different environmental and genetic conditions. At this stage a limited amount of BDO was obtained ( $0.89 \mathrm{mg} \mathrm{L}^{-1}$ under microaerobic conditions on glucose), how ever, further experiments are needed in order to improve the production potential and in case of glycerol to face the redox potential imbalance, that may appear during fermentation.
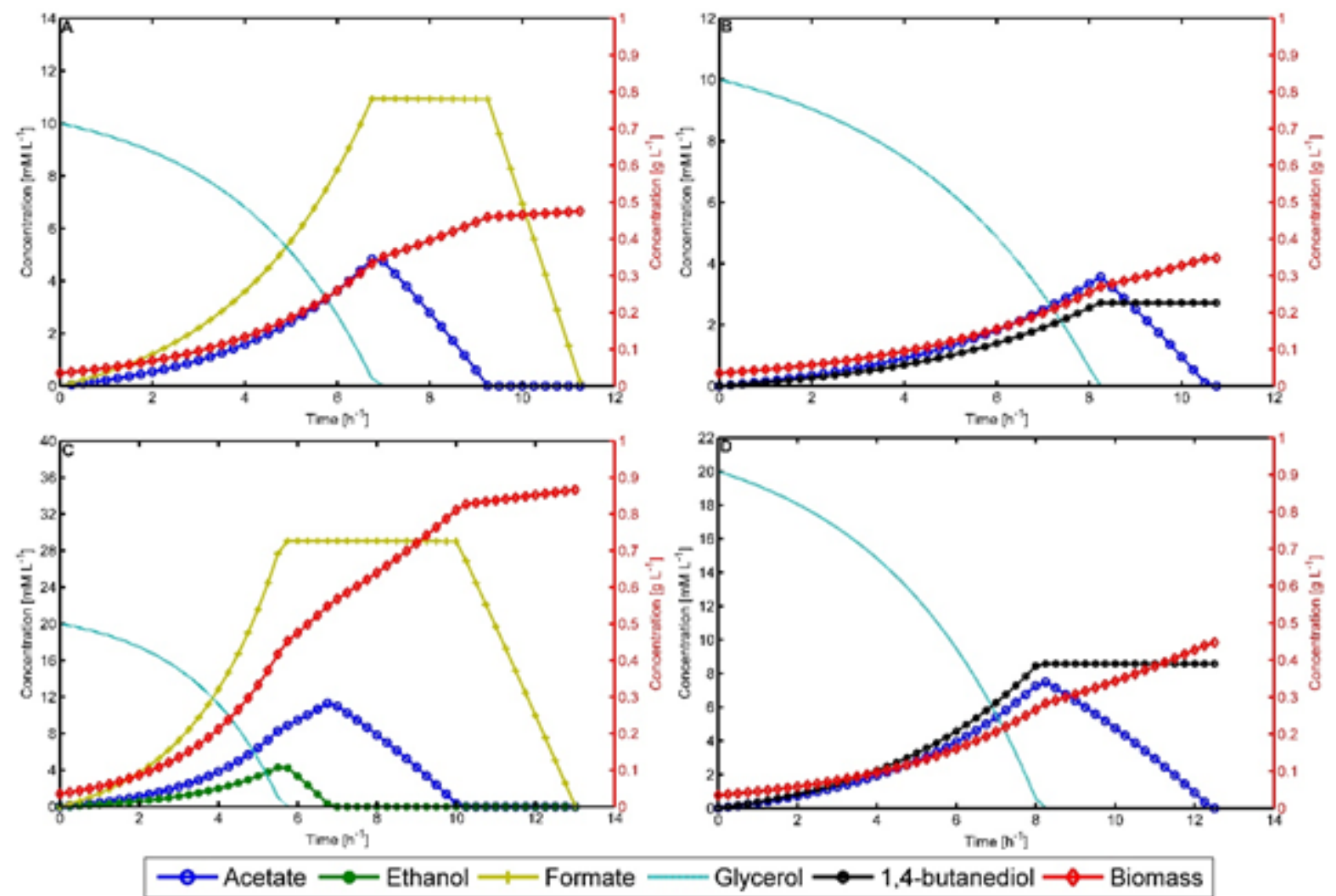

Fig. 8. Model predictions using dFBA for microaerobic and anaerobic conditions (glucose) Microaerobic: WT- A, C, mutant- B, D 


\section{Conclusions}

The development of an efficient cell factory to produce bulk chemicals like BDO is a complex process and requires multiple rounds of the Design-Build-Test-Learn (DBTL) cycle.

Herein we presented a systems biology approach to produce biologically 1,4-butanediol from renewable feedstockes (glucose and glycerol), to identify the potential targets for improved BDO production In the current work the main results are:

a) a new biosynthetic pathway insertion in $E$. coli to produce non-native compound, such as BDO;

b) strain designs that couples the production to growth rate (the new biosynthetic pathway was optimized using different algorithms and totally three and four gene combination was identified for each of the environmental conditions: glucose, glycerol, microaerobic, anaerobic, (uptake rates 10 and $20 \mathrm{mmol}$ for both) which can be experimentally implemented);

c) the production potential design space for non-native product for E. coli was examined and characterized;

d) a recombinant microorganism comprising the new biosynthetic pathway for BDO production from succinyl$\mathrm{CoA}$. Although production yield was far below compared to in silico predictions, or data reported in literature, production can be increased by detailed optimization of fermentation conditions (culture medium, $\mathrm{pH}$, dissolved oxygen), and by long-term (few months) adaptation experiments.

Using the predefined biological parameters in simulations we confirmed that glycerol anaerobically is not a good production feed-stock, how ever microaerobically the BDO yield was over 54 and $77 \%$ of the theoretical yield, respectively. Glucose is a good feedstock for both microaerobic and anaerobic conditions, however the yield difference was nearly $50 \%$ between microaerobic and anaerobic conditions. The achievable percentage of the theoretical maximum was very high anaerobically $95 \%$ for $10 \mathrm{mmol}$ uptake and $80 \%$ for $20 \mathrm{mmol}$ uptake. For heterologous BDO production under microaerobic conditions the most efficient substrate tend to be glycerol, however for glucose a greater production potential can be achieved without oxygen. It can be concluded that metabolites secreted can be further metabolized only if the oxygen is present in a sufficient amount to create microaerobic conditions. Acetate, formate or ethanol cannot be used as potential carbon sources for BDO production. The heterologous pathways were successfully introduced into the host organism and the most important by-products were eliminated by knocking out the genes encoding the pfl, Idh, adhE2 enzymes. The pathway was stable during fermentations carried out in a bioreactor and BDO was detectable in the culture medium after IPTG induction.

The BDO production potential analysis from glycerol is a novel approach with biotechnological importance and should be carefully considered in in vivo strain designs, however, many other factors have to be considered for a sustainable bioprocess for BDO production from glycerol. Harnessing the advantages of biotechnology we would be able to add value to the production of biodiesel, to cope with industrialization issues [82], and make it much more competitive.The key challenges for bio-based production of value-added compounds lie on production costreduction, which can only be addressed by using cheaper substrates and construction of highly efficient microbial strains by systems biology approach.
Acknowledgements: This work was supported by the Romanian Ministry of Education and Scientific Research, [project PN-II-PTPCCA-2013-4-1090, Nr. 44/2014]; Sapientia University [2017/2018 Research Program, grant nr. 227/2/17.05.2017].

\section{References}

1.YIM, H., HASELBECK, R., NIU, W., PUJOL-BAXLEY, C., BURGARD, A., BOLDT, J., KHANDURINA, J., TRAWICK, J.D., OSTERHOUT, R.E., STEPHEN, R., ESTADILLA, J., TEISAN, S., SCHREYER, H.B., ANDRAE, S., YANG, T.H., LEE, S.Y., BURK, M.J., VAN DIEN, S., Nat. Chem. Biol., 7, no. 7, 2011, p. 445

2.NOGALES, J., GUDMUNDSSON, S., THIELE, I., Int. J . Hydrogen Energy, 37, no. 17, 2012, p. 12205.

3. BARTON, N.R., BURGARD, A.P., BURK, M.J., CRATER, J.S., OSTERHOUT, R.E., PHARKYA, P., STEER, B.A., SUN, J., TRAWICK, J.D., VAN DIEN, S.J ., YANG, T.H., YIM, D.H., J. Ind. Microbiol. Biotechnol., 42, no. 3, 2014, p. 349.

4.TOCIU, C., SZEP, R., ANGHEL, A.M., MARINESCU, F., ILIE, M., HOLBAN, E., GHITA, G., MATEI, M., DUMITRU, F.D., POPESCU, I., MONCE, A., LASLO, L., DAESCU, A.I., POPESCU, C.R.G., J. Environ. Prot. Ecol., no.11, 2017, p. 842.

5.HOLBAN, E., DIACU, E., MATEI, M., GHITA, G., RAISCHI, M., FRONESCU, S., DAESCU, A., GHEORGHE, I.P., ILIE, M., SZEP, R., DAESCU, V., DUMITRU, D., MARINESCU, F., TOCIU, C., POPESCU, I., POPESCU, C.R.G. J. Environ. Prot. Ecol., 18, no. 11, 2017, p. 819.

6.SZEP, R., KERESZTES, R., KORODI, A., TONK, S., CRACIUN, M.E., Rev. Chim. (Bucharest), 68, no. 9, 2017, p. 1763.

7.SZEP, R., KERESZTES, R., KORODI, A., TONK, S., NICULAE, A.G., BIRLOIU, A.M., Rev. Chim. (BUcharest), 67, no. 10, 2016, pp. 19141921.

8.SZEP, R., MATEESCU, E., NECHIFOR, A. C., KERESZTESI, A., Environ. Sci. Pollut. Res., 24, no. 35, 2017, p. 27288.

9.SZÉP, R., BODOR, Z., MIKLOSSY, I., NITA, I.A., OPREA, O.A., KERESZTESI, Á., Sci. Total Environ., 647, 2019, pp. 275-289.

10.ERICKSON, B., NELSON, J.E., WINTERS, P., Biotechnol. J., 7, no. 2, 2012, p. 176.

11.ANDREOZZI, S., CHAKRABARTI, A., SOH, K.C., BURGARD, A., YANG, T.H., VAN DIEN, S., MISKOVIC, L., HATZIMANIKATIS, V., Metab. Eng., 35, 2016, p. 148.

12.NIELSEN, J., KEASLING, J.D., Cell, 164, no. 6, 2016, p. 1185.

13.TRACY M.C., JOAN, P., MARK D.P., Appl. Biochem. Biotechnol., 113-116, 2004, p. 871.

14.PLÁCIDO, J., CAPAREDA, S., Bioresour. Bioprocess., 3, no. 23, 2016, p. 1.

15.WANG, J., JAIN, R., SHEN, X., SUN, X., CHENG, M., LIAO, J.C., YUAN, Q., YAN, Y., Metab. Eng., 40, 2017, p. 148.

16.ZHANG, Y., LIU, D., CHEN, Z., Biotechnol. Biofuels, 10, no. 1, 2017, p. 1.

17.LIU, H. LU, T., Metab. Eng., 29, 2015, p. 135.

18.BURGARD, A., BURK, M. J., OSTERHOUT, R., VAN DIEN, S., YIM, H., Curr. Opin. Biotechnol., 42, 2016, p. 118.

19.BIBOLET, E.R., FERNANDO, G.E., SHAH, S.M., CBE Senior Design Project, Univ. Pennsylvania, 2011, p. 242.

20.HWANG, H. J., PARK, J.H., KIM, J.H., KONG, M.K., KIM, J.W., PARK, J.W., CHO, K.M., LEE, P.C., Biotechnol. Bioeng., 111, no. 7, 2014, p. 1374.

21.TAI, Y.-S., XIONG, M., JAMBUNATHAN, P., WANG, J., WANG, J., STAPLETON, C., ZHANG, K. Nat. Chem. Biol., 12, no. 4, 2016, p. 247. 22.de JONG, B., SIEWERS, V., NIELSEN, J., Curr. Opin. Biotechnol., 23, no. 4, , 2012, p. 624.

23.CHEN, X., ZHOU, L., TIAN, K., KUMAR, A., SINGH, S., PRIOR, B.A., WANG, Z., Biotechnol. Adv., 31, no. 8, 2013, p. 1200.

24.WOOLSTON, B.M., EDGAR, S., STEPHANOPOULOS, G., Annu. Rev. Chem. Biomol. Eng., 4, no. 1, 2013, p. 259.

25.YU, C., CAO, Y., ZOU, H., XIAN, M., Appl. Microbiol. Biotechnol., 89, no. 3, 2011, p. 573. 
26.FORSTER A.H., GESCHER, J., Front. Bioeng. Biotechnol., 2, no. 5, 2014, p. 16.

27.BORODINA, I., KILDEGAARD, K.R., JENSEN, N.B., BLICHER, T.H., MAURY, J., SHERSTYK, S., SCHNEIDER, K., LAMOSA, P., HERRGARD, M.J., ROSENSTAND, I., ÖBERG, F., FORSTER, J., NIELSEN, J., Metab. Eng., 27, 2015, p. 57.

28.KIM, I.K., ROLDAO, A., SIEWERS, V., NIELSEN, J., FEMS Yeast Research, 12, no. 2., 2012, p. 228.

29.BURGARD, A.P., OSTERHOUT, R.E., SUN, J., PHARKYA, P., US 2013/ 0034884, 2013.

30.NAKAMURA C.E., WHITED, G.M., Curr. Opin. Biotechnol., 14, no. 5, 2003, p. 454.

31.LEE, J.H., JUNG, M.Y., OH, M.K., Biotechnol. Biofuels, 11, no. 1, 2018, p. 1.

32.SONG H., LEE, S.Y., Enzyme Microb. Technol., 39, no. 3, 2006, p. 352.

33.BODOR, Z., FAZAKAS (IUHASZ), A., KOVACS, E., LANYI, S., ALBERT, B., Rom. Biotechnol. Lett., 19, no. 4, 2014, p. 9625.

34.CLOMBURG, J.M., GONZALEZ, R., Biotechnol. Bioeng., 108, no. 4, 2011, p. 867.

35.ATSUMI, S., CANN, A.F., CONNOR, M.R., SHEN, C.R., SMITH, K.M., BRYNILDSEN, M.P., CHOU, K.J.Y., HANAI, T., LIAO, J.C., Metab. Eng., 10, no. 6, 2008, p. 305.

36.AYOUB, M., ABDULLAH, A.Z., Renew. Sustain. Energy Rev., 16, no. 5, 2012, p. 2671.

37.da SILVA, G.P., MACK, M., CONTIERO, J., Biotechnology Advances, 27, no. 1. 2009, p. 30.

38.WENDISCH, V.F., LINDNER, S.N., MEISWINKEL, T.M., Biodiesel Qual. Emiss. By-Products, 2011, p. 305.

39.SARMA, S., ANAND, A., DUBEY, V.K., MOHOLKAR, V.S., Bioresour. Technol., 242, 2017, p. 169.

40. KIM, B., KIM, W.J ., KIM, D.I., LEE, S.Y., J. Ind. Microbiol. Biotechnol., 42, no. 3, 2014, p. 339.

41.LONG, M.R., ONG, W.K., REED, J.L., Curr. Opin. Biotechnol., 34, 2015, p. 135.

42.KING, Z.A., LLOYD, C.J., FEIST, A.M., PALSSON, B.O., Curr. Opin. Biotechnol., 35, 2015, p. 23.

43.PRICE, N.D., PAPIN, J.A., SCHILLING, C.H., PALSSON, B.O., Trends Biotechnol., 21, no. 4, 2003, p. 162.

44.FEIST, A.M., ZIELINSKI, D.C., ORTH, J.D., SCHELLENBERGER, J., HERRGARD, M.J., PALSSON, B.O., Metab. Eng., 12, no. 3, 2010, p. 173. 45.KIM, H.U., KIM, B., SEUNG, D.Y., LEE, S.Y., Biotechnol. Bioprocess Eng., 667, 2014, p. 660.

46.O'BRIEN, E.J., MONK, J.M., PALSSON, B.O., Cell, 161, no. 5, 2015, p. 971.

47.LIU, T., ZOU, W., LIU, L., CHEN, J., Biotechnol. Biofuels, 5, no. 1, 2012, p. 72.

48.KIM, W.J ., KIM, H.U., LEE, S.Y., Current Opinion in Systems Biology, 2, 2017, p. 10.

49.ORTH, J.D., CONRAD, T.M., NA, J., LERMAN, J.A., NAM, H., FEIST, A.M., PALSSON, B.Ø., Mol. Syst. Biol., 7, 2011, p. 1.

50.BURGARD, A.P., PHARKYA, P., MARANAS, C.D., Biotechnol. Bioeng., 84, no. 6, 2003, p. 647.

51.LUN, D.S., ROCKWELL, G., GUIDO, N.J ., BAYM, M., KELNER, J.A., BERGER, B., GALAGAN, J.E., CHURCH, G.M., Mol. Syst. Biol., 5, no. 296, 2009, p. 296.

52.MAHADEVAN, R., EDWARDS, J.S., DOYLE, F.J ., Biophys. J., 83, no. 3, 2002, p. 1331.

53.BECKER, S.A., FEIST, A.M., MO, M.L., HANNUM, G., PALSSON, B.Ø., HERRGARD, M.J., Nat. Protoc., 2, no. 3, 2007, p. 727.

54.DATSENKO, K.A., WANNER, B.L., Proc. Natl. Acad. Sci. U. S. A., 97, no. 12,2000, p. 6640.
55.MIKLOSSY, I., BODOR, Z., SINKLER, R., ORBAN, K.C., LAANYI, S., ALBERT, B., J. Biomol. Struct. Dyn., 35, no. 9, 2016, p. 1874.

56.LEWIS, N.E., HIXSON, K.K., CONRAD, T.M., LERMAN, J.A. CHARUSANTI, P., POLPITIYA, A.D., ADKINS, J.N., SCHRAMM, G., PURVINE, S.O., LOPEZ-FERRER, D., WEITZ, K.K., EILS, R., KÖNIG, R., SMITH, R.D., PALSSON, B.O., Mol. Syst. Biol., 6, no. 390, 2010, p. 390.

57.CONRAD, T.M., LEWIS, N.E., PALSSON, B.O., Mol. Syst. Biol., 7, no. 509, 2011, p. 509.

58.IBARRA, R.U., EDWARDS, J.S., PALSSON, B.O., Nature, 420, no. 6912, 2002, p. 186.

59.FONG, S.S., BURGARD, A.P., HERRING, C.D., KNIGHT, E.M., BLATTNER, F.R., MARANAS, C.D., PALSSON, B.O., Biotechnol. Bioeng., 91, no. 5, 2005, p. 643.

60.VARMA, A., BOESCH, B.W., PALSSON, B.O., Appl. Environ. Microbiol., 59, no. 8, 1993, p. 2465.

61.VARMA, A., PALSSON, B.O., Appl. Environ. Microbiol., 60, no. 10, 1994, p. 3724.

62.HASELBECK, R., TRAWICK, J.D., NIU, W., BURGARD, A.P., US 2013/ 0029381, 2013.

63.BURK, M.J., BURGARD, A.P., OSTERHOUT, R.E., SUN, J., US 2013/ 0071886A1, 2013.

64.THIELE, I., PALSSON, B.O., Nat. Protoc., 5, no. 1, 2010, p. 93.

65.ORTH, J.D., THIELE, I., PALSSON, B.O., Nat. Biotechnol., 28, no. 3, 2010, p. 245.

66.MILNE, C.B., KIM, P.J ., EDDY, J.A., PRICE, N.D., Biotechnol. J., 4, no. 12, 2009, p. 1653.

67.SCHELLENBERGER, J., QUE, R., FLEMING, R.M.T., THIELE, I., ORTH, J.D., FEIST, A.M., ZIELINSKI, D.C., BORDBAR, A., LEWIS, N.E., RAHMANIAN, S., KANG, J., HYDUKE, D.R., PALSSON, B.O., Nat. Protoc., 6, no. 9, 2011, p. 1290.

68.CAMPODONICO, M.A., ANDREWS, B.A., ASENJ O, J.A., PALSSON, B.Ø., FEIST, A.M., Metab. Eng., 25, 2014, p. 140.

69.MAHADEVAN, R., SCHILLING, C.H., Metab. Eng., 5, no. 4, 2003, p. 264.

70.BABA, T., ARA, T., HASEGAWA, M., TAKAI, Y., OKUMURA, Y., BABA, M., DATSENKO, K.A., TOMITA, M., WANNER, B.L., MORI, H., Mol. Syst. Biol., 2, 2006.

71.J OYCE, A.R., PALSSON, B.O., Methods Mol. Biol., 416, no. 2, 2008, p. 433.

72.J OYCE, A.R., REED, J.L., WHITE, A., EDWARDS, R., OSTERMAN, A., BABA, T., MORI, H., LESELY, S.A., PALSSON, B. Ø., AGARWALLA, S., J. Bacteriol., 188, no. 23, 2006, p. 8259.

73.HOFFNER, K., HARWOOD, S.M., BARTON, P.I., Biotechnol. Bioeng., 110, no. 3, 2013, p. 792.

74.YANG, F., HANNA, M.A., SUN, R., Biotechnol. Biofuels, 5, no. 1, 2012, p. 13.

75.YAZDANI, S.S., GONZALEZ, R., Metab. Eng., 10, no. 6, 2008, p. 340. 76.MURARKA, A., DHARMADI, Y., YAZDANI, S.S., GONZALEZ, R., Appl. Environ. Microbiol., 74, no. 4, 2008, p. 1124.

77.WOLFE, A.J., Microbiol. Mol. Biol. Rev., 69, no. 1, 2005, p. 12.

78.PICON, A., TEIXEIRA DE MATTOS, M.J., POSTMA, P.W., Biotechnol. Bioeng., 90, no. 2, 2005, p. 191.

79.BÄCKLUND, E., IGNATUSHCHENKO, M., LARSSON, G., Microb. Cell Fact., 10, no. 1, 2011, p. 35.

80.ZHUANG, K., YANG, L., CLUETT, W.R., MAHADEVAN, R., BMC Biotechnol., 13, 2013, p. 8.

81.OLDIGES, M., EIKMANNS, B.J., BLOMBACH, B., Appl. Microbiol. Biotechnol., 98, no. 13, 2014, p. 5859.

82.SZEP, R., MATEESCU, E., NITA, A., BIRSAN, M., BODOR, Z., KERESZTESI, A., Atmos. Res., doi:10.1016/j.atmosres.2018.08.009, xxx, 2018.

Manuscript received: 28.08 .2019 